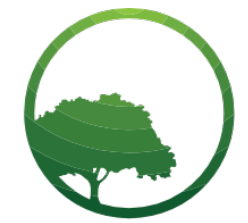

Business \& Social Science

\section{Research in Business and Social Science}

IJRBS Vol 8 No 4, ISSN: 2147-4478

Contents available at www.ssbfnet.com/ojs

\title{
Online Video Games Adoption: Toward an Online Game Adoption Model
}

\section{Mohammed Hokroh}

Corresponding Author: Ph.D., School of Business, University of Bolton, Bolton, United Kingdom. ORCID ID: 0000-0001-6494-6370

\section{Gill Green}

Ph.D., School of Business, University of Bolton, Bolton, United Kingdom.

ORCID ID: 0000-0001-9665-0734

\begin{abstract}
The purpose of this research paper is to explore the factors that influence Saudi users to adopt and use online video games. We developed a theoretical framework based on the Technology Adoption Model (TAM) to examine 6 hypotheses through a survey of 106 video game users. The results indicate that social norms, perceived enjoyment and social interaction play a positive and significant role in influencing the perceived usefulness of online video games for end users. Also, price value, game quality and internet speed were all factors that influence end user perceived ease of use of online video games. Both perceived ease of use and perceived usefulness were all of significant influence to the attitude to use online video games. Furthermore, perceived usefulness and attitude to use online video games influenced the behavioral intention to use online video games which in return influenced the actual use.
\end{abstract}

Key words: System Adoption, TAM, Video Games, Saudi Arabia

JEL classification: $015, P 36$

Submitted: 12.05.2019 - Accepted: 16.06.2019

\section{Introduction}

'Online video game' refers to virtual reality or simulation games in which two or more players interact with or compete against each other using their own devices. Online video gaming has emerged as a new phenomenon worth addressing in terms of factors influencing adoption which motivted the researchers to 
conduct this study. This study enables researchers to better understand how people interact with emerging technology. Also, we extend theory into practice by applying it in different contexts. Technology adoption is of interest to the Management Information Systems' (MIS) research due to the ever evolving nature of technology and humans. As technology evolves, understanding the factors that influence adoption is critical in order to better understanding.

Since the emergence of video games industry in 1970s, it has quickly become formidable industry of significant size and complexity. Thus, requiring variety of technical and art skills (Izushi and Aoyama (2006)). Chang et al. (2006) pointed out that the online video game industry generated a revenue of $\$ 54.7$ billion in 2001, an amount that will be tripled with the expectations to reach $\$ 188.9$ billion by 2020 according to Balakrishnan and Griffiths (2018). Aoyama and Izushi (2003) pointed out that video games have had pervasive influences on general culture. However, little is known about this industry in terms of creative resources, formation and sources of completion. Therefore, entities interested in investing in this field may better compete if they had more knowledge about how end users (consumers) interact and adopt online games.

In this research we ask the question, 'what are the factors that influence online video games adoption'? We answer this question by extending the Technology Adoption Model (TAM) through identifying six major factors that influence Saudi end users to adopt and use online games. We surveyed 106 users and analyzed the data using regression analysis. As far as we know, this is the first research focused on online video games adoption in the Saudi Arabian context. The findings revealed that there are six important factors that play a critical role in online video games adoption, and addressing these factors enhances the adoption process.

This research starts with a literature review defining TAM and discussing the factors that influence adoption of online video games. In the methodology section, we explain the survey instrument and data analysis which covers the survey validity, reliability and regression analysis.

\section{Literature Review}

The Technology Acceptance Model (TAM) is considered a predominant theory in the technology adoption field. TAM has two main constructs which are Perceived Ease of Use (PEU) and Perceived Usefulness (PU).

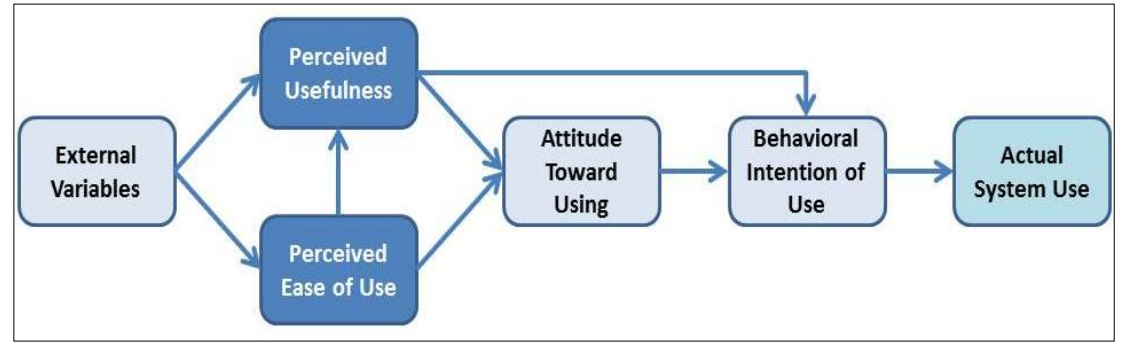

Figure 1: The Technology Acceptance Model (TAM)

PU is defined as the degree to which a user believes that using a particular system would enhance his or her performance. PEU refers to the degree to which a person believes that using a system would be free of effort. External variables will either influence PEU or PU which in return may influence attitude toward system use. PEU will influence PU and PU will influence the behavioural intention of system use. (Davis 1989) 


\section{Hokroh \& Green / International Journal of Research in Business and Social Science,}

Vol 8 No 4, 2019 ISSN: 2147-4486

According to Al-Somali et al. (2009), TAM has been found to be a powerful, highly reliable, valid and robust predicative model. TAM has been used extensively in the literature with extended constructs or in conjunction with other models (e.g. Al-Harbi (2011), Al-Gahtani (2011), Smarkola (2008) and Al-Somali et al. (2009)).

The MIS literature has identified several factors that influence system adoption in general and specifically in Saudi Arabia, however, these factors have yet to be tested in the online game context.

As defined by Glanz et al. (2008), social influence refers to how "important others" will evaluate the performance of a particular behaviour and the willingness of a person to be guided by their evaluation. Therefore, a user will be willing to use a new system guided by the behavior of their peers. Social influence in Saudi Arabia has been found to be an important factor in influencing system adoption and use (Al-Gahtani et al. (2007) and Al-Harbi (2011)). According to the literature, Arabs pose a particular importance to social norms and are more likely to be influenced by peers, friends or family. Therefore, it is assumed that online gamers are more likely to adopt a game when being influenced by peers or friends.

Hypothesis 1: social norms positively influence video games adoption.

Having a high speed internet service is important to users. As Simsim (2011) pointed out that improving the speed and quality of the internet connection in Saudi Arabia were found to be more important than decreasing the price of the service. Al-Somali et al. (2009) found that the quality of internet connection is a significant factor that influenced online banking acceptance in Saudi Arabia. Clearly, online games will require users to have a decent internet connection speed in order to have a full online game experience. Therefore, it suggested that having a high speed connection will influence online games to adopt online games.

Hypothesis 2: high speed internet service positively influences video games adoption.

Perceived enjoyment, intrinsic or hedonic motivation refers to the feeling of satisfaction and pleasure driven from an activity, where the reward is the activity itself, independent of external reinforcements. O'Brien (2010) and Venkatesh et al. (2012)

According to Venkatesh et al. (2012), perceived enjoyment has been shown to play a significant role in technology acceptance. O'Brien (2010) pointed out that system developers need to design systems that incorporate the hedonic motivation component which is manifested in user feedback when they are engaged in the system. Similar to other systems, the user of online games is suggested to be influenced by perceived enjoyment of the online games.

Hypothesis 3: perceived enjoyment positively influences video games adoption.

As defined by Venkatesh et al. (2012), price value is the perceived benefits of using a particular technology or system and the monetary cost associated with using it. Kim et al. (2007) pointed out that perception of value of mobile-internet consumers is a principal determinant of adoption intention moderated through perceived value. According to Kim et al. (2007), perceived value is treated as a trade-off between the 'give' and 'get' components of a product and therefore it is subjective to the consumer overall assessment of the perceived value. Therefore, as the online games price value and quality increase, users are suggested be more influenced to adopt and use the online games.

Hypothesis 4: lower price value positively influences video games adoption.

Hypothesis 5: higher quality value positively influences video games adoption.

Social interaction is not social influence. Social influence refers to peers influence on user to adopt a game while social interaction refers to the interaction between peers and user when playing an online game. Choi and Kim (2004) defined social interaction as interaction between a user and other two or more users of the 
same system. As pointed out by Choi and Kim (2004), end users will show higher levels of loyalty toward an online game if it leads to an optimal experience derived from social interaction. Chen and Duh (2007) pointed out that the MIS literature highlights the importance of social interaction is being a primary driving force for gamers to play games. As a result, it is suggested that online gamers are more likely to adopt a game if it offers social interaction with other players.

Hypothesis 6: social interaction positively influences video games adoption.

\section{Research and Methodology}

A survey instrument was developed to test the research hypotheses. In addition to the demographic variables of gender, age and education, seven main questions were developed to test each hypothesis. Participants were asked to rate each question via Likert scale of 1 to 5 with 5 being "strongly agree" and 1 being "strongly disagree".

The survey started on August $25^{\text {th }} 2018$ and concluded on October $6^{\text {th }} 2018$. A sample of 112 online video game users were randomly selected from the Saudi Eastern Province community. However, a total of 106 useable responses were collected after removing uncompleted surveys yielding a response rate of $95 \%$ (106/112). The survey was directly delivered to participants. We used the help of some surveyed users to redistribute the survey to their friends, colleagues or family members.

We started our data analysis by delivering descriptive statistics of the surveyed sample before testing the survey instrument validity and reliability. We then proceeded with regression analysis and builtup the research path model. We used Statistical Package for the Social Sciences (SPSS) and Analysis of a Moment Structures (AMOS) to conduct our statistical data analysis.

Descriptive statistics of our surveyed sample which revealed that $64 \%$ of surveyed sample were males and $36 \%$ females. The majority of the surveyed sample (68\%) were between ages of $18-25$ while $24 \%$ were between $26-35$ years and only $8 \%$ were between $36-45$ years old. On the other hand, $61 \%$ of the surveyed sample were college students or graduates, $33 \%$ were high school students or graduates and $6 \%$ were postgraduate students or graduates.

Table 2: Descriptive Statistics

\begin{tabular}{|c|c|c|c|c|c|c|c|c|}
\hline \multirow{2}{*}{ Gender } & \multicolumn{4}{|c|}{ Age } & \multicolumn{4}{c|}{ Education } \\
\cline { 2 - 9 } & $\mathbf{1 8 - 2 5}$ & $\mathbf{2 6 - 3 5}$ & $\mathbf{3 6 - 4 5}$ & Total & $\begin{array}{c}\text { High } \\
\text { School }\end{array}$ & Undergraduate & Postgraduate & Total \\
\hline Male & 40 & 20 & 8 & $\mathbf{6 8}$ & 8 & 54 & 6 & $\mathbf{6 8}$ \\
\hline Female & 32 & 6 & 0 & $\mathbf{3 8}$ & 27 & 11 & 0 & $\mathbf{3 8}$ \\
\hline Total & $\mathbf{7 2}$ & $\mathbf{2 6}$ & $\mathbf{8}$ & $\mathbf{1 0 6}$ & $\mathbf{3 5}$ & $\mathbf{6 5}$ & $\mathbf{6}$ & $\mathbf{1 0 6}$ \\
\hline
\end{tabular}

As pointed out by Ghadi et al. (2012), discriminant validity indicates that instrument items that are supposed to be not related, are in fact not related. On the other hand, convergent validity indicates the instrument items that are supposed to related, are in fact related. According to Ghadi et al. (2012), if two variables correlation value exceeded that of 0.9 , then they are said to have significantly overlapping constructs. Our survey correlation matrix revealed the survey instrument validity. 


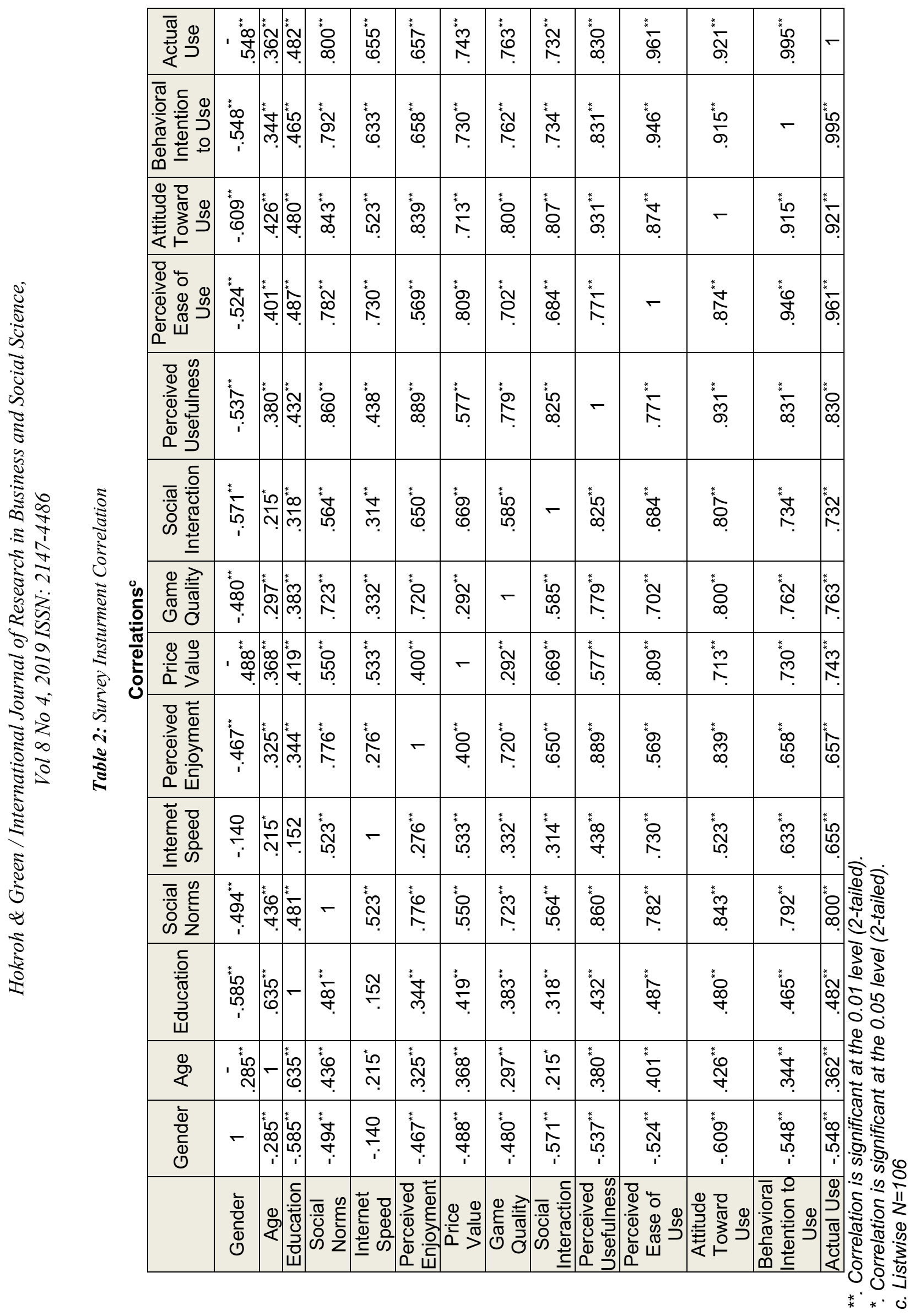


Reliability analysis revealed a Cronbach Alpha of 0.937 . Joppe cited in Golafshani (2003) defined reliability as "the extent to which results are consistent over time and an accurate representation of the total population under study" (p. 598). In other words if the results of a study can be reproduced under similar methodological approach, then the research instruments are considered reliable. According to Sarli and Baharun (2016), if Cronbach's Alpha yielded a value of more than 0.7 , then the constructs are regarded as highly reliable.

Regression analysis is a statistical technique that researchers use to analyze the relationship between a single dependent (criterion) variable and several independent (predictor) variables. This allows the researcher to use the independent variables whose values are known to predict a single dependent value that he or she selects. Hair et al. (1998)

Regression weight loading revealed a significant association between each dependent and independent variables with statistical significance of $p$-value $<0.05$.

Table 3: Regression Weights

\begin{tabular}{|c|c|c|c|c|c|}
\hline $\begin{array}{l}\text { Dependent } \\
\text { Variables }\end{array}$ & $\begin{array}{l}\text { Independent } \\
\text { Variables }\end{array}$ & $\begin{array}{c}\text { Standardized } \\
\text { Estimates } \\
(\boldsymbol{\beta})\end{array}$ & S.E. & C.R. & $\begin{array}{c}P- \\
\text { Value }\end{array}$ \\
\hline Perceived Ease of Use & Price Value & .558 & .010 & 33.934 & $* * *$ \\
\hline Perceived Ease of Use & Game Quality & .610 & .010 & 33.934 & $* \star *$ \\
\hline Perceived Ease of Use & Internet Speed & .483 & .010 & 33.934 & $* \star *$ \\
\hline Perceived Usefulness & Social Norms & .534 & .011 & 29.015 & $\star \star \star *$ \\
\hline Perceived Usefulness & Perceived Enjoyment & .564 & .011 & 29.015 & $* * *$ \\
\hline Perceived Usefulness & Perceived Interaction & .535 & .011 & 29.015 & $\star \star \star *$ \\
\hline Attitude Toward Use & Perceived Ease of Use & .610 & .025 & 19.367 & $* * *$ \\
\hline Attitude Toward Use & Perceived Usefulness & .640 & .025 & 19.367 & 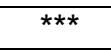 \\
\hline $\begin{array}{c}\text { Behavioral Intention to } \\
\text { Use }\end{array}$ & Attitude Toward Use & .355 & .035 & 11.445 & 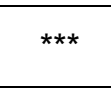 \\
\hline $\begin{array}{c}\text { Behavioral Intention to } \\
\text { Use }\end{array}$ & Perceived Usefulness & .466 & .035 & 11.445 & *** \\
\hline Actual Use & $\begin{array}{c}\text { Behavioral Intention to } \\
\text { Use }\end{array}$ & .990 & .013 & 72.102 & $* * *$ \\
\hline
\end{tabular}

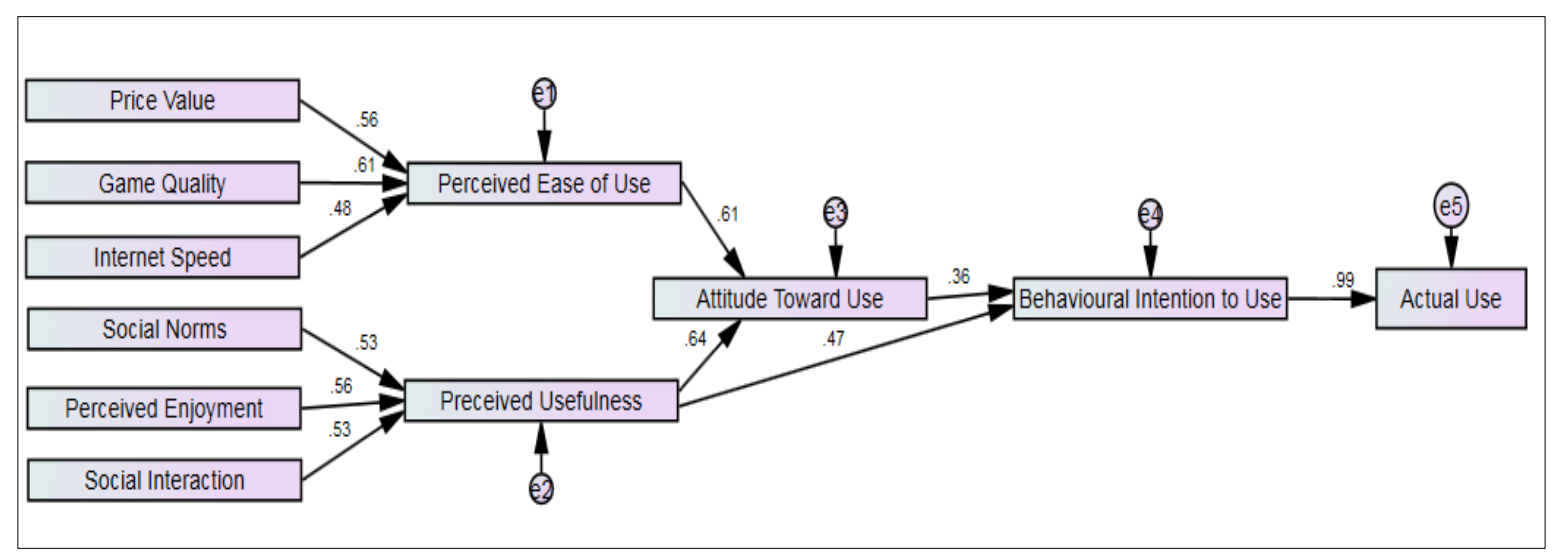

Figure 2: Research Path Model 


\section{Result and Discussion}

The six proposed hypothesis were supported. Analysis results indicate that social norms, perceived enjoyment and social interaction play positive significant role in influencing end users perceived usefulness of online video games. Also, price value, game quality and internet speed were all found to influence end user perceived ease of use of video online games.

Both perceived ease of use and perceived usefulness were all of significant influence to the attitude to use video online games. Perceived usefulness of online video games and attitude to use video online games both influenced the behavioral intention to use online video games which in return influenced actual use.

Game quality was found to have the strongest influence on perceived ease of use while perceived enjoyment was found to have the strongest influence on perceived usefulness. This may be attributed to the quality of the game. Thus, one feature of quality is ease of use which in return increased perceived enjoyment. On the other hand, although perceived ease of use had a strong influence on attitude toward use, perceived usefulness had a stronger influence. This may be attributed to social norms, perceived enjoyment and social interaction which are important elements to online gamers.

Perceived usefulness had a strong influence on behavioral intention to use online video game which resulted in the actual use. Thus, indicating the importance of social norms, perceived enjoyment and social interaction as key elements of adoption.

Despite these findings, the research is not without limitations. First, we did not look at the correlation between age and the suggested factors for adoption. Furture research may look into the link between age and adoption factors. Second is gender link to the adoption factors. Furture research may look into the link between age and adoption factors. Third, future reseach may look into a spreicifc market niche and link it to the adoption factors.

\section{Conclusions}

In this research we explored the factors that influence Saudi users to adopt and use online video games. We developed a theoretical framework based on the Technology Adoption Model (TAM) and surveyed a total of 106 online video game users.

The findings indicate that social norms, perceived enjoyment and social interaction play positive significant role in influencing end users perceived usefulness of online video games. On the other hand, price value, game quality and internet speed were all factors influence end user perceived ease of use of online video games. Both perceived ease of use and perceived usefulness were all of significant influence to the attitude to use online video games. Perceived usefulness and attitude to use online video games influenced the behavioral intention to use online video games which in return influenced the actual use.

This research paper has some limitations that maybe addressed by future research. First, we did not look at the correlation between age and the suggested factors for adoption. Furture research may look into the link between age and adoption factors. Second is gender link to the adoption factors. Furture research may look into the link between age and adoption factors. Third, future reseach may look into a spreicifc market niche and link it to the adoption factors.

\section{References}

Al-Gahtani, S. S. (2011). Modelling the Electronic Transaction Acceptance Using an Extended Technology Acceptance Model. Applied Computing and Informatics 9, 47-77. https://doi.org/10.1016/j.aci.2009.04.001

Al-Gahtani, S., Hubona, G. and Wang, J. (2007). Information technology (IT) in Saudi Arabia: Culture and the Acceptance and Use of IT. Information and Management 44, 681-691. https://doi.org/10.1016/j.im.2007.09.002

Aoyama, Y., and Izushi, H. (2003). Hardware gimmick or cultural innovation? Technological, cultural, and social foundations of the Japanese video game industry. Research policy, 32(3), 423-444 
Hokroh \& Green / International Journal of Research in Business and Social Science,

Vol 8 No 4, 2019 ISSN: 2147-4486

https://doi.org/10.1016/S0048-7333(02)00016-1

Izushi, H., and Aoyama, Y. (2006). Industry evolution and cross-sectoral skill transfers: a comparative analysis of the video game industry in Japan, the United States, and the United Kingdom. Environment and planning A, 38(10), 1843-1861. https://doi.org/10.1068/a37205

Al-Harbi, K. (2011). E-learning in the Saudi Tertiary Education: Potential and Challenges. Applied Computing and Informatics 9, 31-46. https://doi.org/10.1016/j.aci.2010.03.002

Al-Somali, S. A., Gholami, R. and Clegg, B. (2009). An Investigation into the Acceptance of Online Banking in Saudi Arabia. Technovation 29, 130-141. https://doi.org/10.1016/j.technovation.2008.07.004

Balakrishnan, J. and Griffiths, M. D. (2018). Loyalty towards online games, gaming addiction, and purchase intention towards online mobile in-game features. Computers in Human Behavior. https://doi.org/10.1016/j.chb.2018.06.002

Chang, B. H., Lee, S. E., \& Kim, B. S. (2006). Exploring factors affecting the adoption and continuance of online games among college students in South Korea: Integrating uses and gratification and diffusion of innovation approaches. New Media \& Society, 8(2), 295-319. https://doi.org/10.1177/1461444806059888

Chen, V. H. H. and Duh, H. B. L (2007). Understanding social interaction in world of Warcraft. In Proceedings of the international conference on Advances in computer entertainment technology (pp. 21-24) ACM. DOI: 10.1145/1255047.1255052

Choi, D. and Kim, J. (2004). Why people continue to play online games: In search of critical design factors to increase customer loyalty to online contents. Cyber Psychology and Behaviour, 7(1), 11-24. https://doi.org/10.1089/109493104322820066

Davis, F. D. (1989). Perceived Usefulness, Perceived Ease of Use and User Acceptance of Information Technology. MIS Quarterly 13, 319-340. DOI: 10.2307/249008

Ghadi, I., Alwi, N. H., Bakar, K. A., and Talib, O. (2012). Construct validity examination of critical thinking dispositions for undergraduate students in University Putra Malaysia. Higher Education Studies, 2(2), 138. http://dx.doi.org/10.5539/hes.v2n2p138

Glanz, K., Rimer, B. K., and Viswanath, K. (2008) Health Behaviour and Health Education: Theory, Research, and Practice. (Eds.) John Wiley and Sons.

Golafshani, N. (2003) Understanding reliability and validity in qualitative research. The Qualitative Report, 8(4), 597-606. https://nsuworks.nova.edu/tqr/vol8/iss4/6

Hair, J., Anderson, R., Tatham, R. and Black, W. (1998). Multivariate Data Analysis., Prentice Hall, Upper Saddle River, New Jersey 07458.

Kim, H. W., Chan, H. C. and Gupta, S. (2007) . Value-based adoption of mobile internet: an empirical investigation. Decision Support Systems, 43(1), 111-126. https://doi.org/10.1016/j.dss.2005.05.009

O.Brien, H. (2010). The influence of hedonic and utilitarian motivations on user engagement: The case of online shopping experiences. Interacting with Computers 22, 344-352. https://doi.org/10.1016/j.intcom.2010.04.001

Sarli, A. and Baharun, R. (2016). Modelling and Statistical Concepts in Business Research: AMOS and SPSS, Lexington, KY: USA.

Simsim, M. T. (2011). Internet usage and user preferences in Saudi Arabia. Journal of King Saud UniversityEngineering Sciences, 23(2), 101-107. https://doi.org/10.1016/j.jksues.2011.03.006

Smarkola, C. (2008). Efficacy of a planned behaviour model: Beliefs that contribute to computer usage intentions of student teachers and experienced teachers. Computers In Human Behaviour 24, 1196-1215. https://doi.org/10.1016/j.chb.2007.04.005

Venkatesh, V., Thong J. and Xu Xin (2012). Consumer Acceptance and Use of Information Technology: Extending the Unified Theory of Acceptance and Use of Technology. MIS Quarterly 36:157178. https://ssrn.com/abstract $=2002388$ 
Hokroh \& Green / International Journal of Research in Business and Social Science,

Vol 8 No 4, 2019 ISSN: 2147-4486

\section{Survey Instrument}

Gender:
1. Male
2. Female

Age:
1. $18-25$
2. $26-35$
3. $36-45$

Education:
1. High School
2. Undergraduate
3. Postgraduate

Please rate the following questions on a scale of 1 to 5 , with 5 being "strongly agree" and 1 being "strongly disagree".

1. My friends playing online games positively influence me to play online games?
1. strongly disagree
2. disagree
3. neither
4. agree
5. strongly agree

2. High speed internet service positively influences me to play online games?
1. strongly disagree
2. disagree
3. neither
4. agree
5. strongly agree

3. I continuously play an online game that I find enjoyable?
1. strongly disagree
2. disagree
3. neither
4. agree
5. strongly agree

4. Lower price value positively influences video games adoption?

$\begin{array}{lllllllll}\text { 1. strongly disagree } & \text { 2. } & \text { disagree } & \text { 3. } & \text { neither } & 4 . & \text { agree } & 5 . & \text { strongly agree }\end{array}$

5. Despite its cost, I will continue to play online games that I consider of high quality?

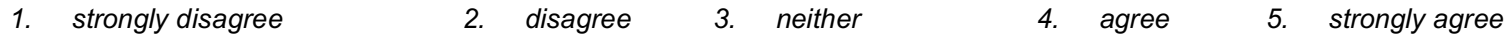

6. Interaction with other online players positively influences me to play online games?

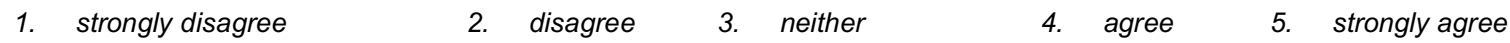

